\title{
The Green and Digital Transformation - the New Challenges of the Construction Market
}

\author{
Aneta Marichova
}

\begin{abstract}
The new EU industrial strategy proposes new measures to strengthen the sustainability of the European single market (especially in times of crisis) and to accelerate the green and digital transformation. It focuses on 14 industrial ecosystems (one of which is construction), which face the most important challenges of achieving the climate, sustainability and digital transformation goals that are key to market competitiveness. The purpose of the study is: 1) Analysis of the problems related to the need to accelerate the green and digital transformation of the construction market, 2) Development of models that support and ensure the double transition in the construction market.
\end{abstract}

Keywords - construction market, green and digital transformation, models that support and ensure the double transformation

\section{INTRODUCTION}

The updated EU Industrial Strategy for 2020 proposes new measures to strengthen the sustainability of the European single market (especially in times of crisis) and to accelerate the green and digital transformation [1]. The aim is to create an innovative, clean and sustainable industry that provides quality jobs and allows companies (especially SMEs) to thrive even during the recovery process.

The EU's industrial strategy focuses on deepening (harmonizing standards for key business activities and services) and monitoring the single market, which includes 14 industrial ecosystems, one of which is construction. The main task is to give priority to ecosystems and sectors that face the most important challenges of achieving the goals of climate, sustainability and digital transformation and are key to the competitiveness of energy-intensive industries (chemical, steel, construction), as well as sectors severely affected by the crisis (tourism, transport).

Green and digital transformation of the economy are a factor in ensuring competitiveness, but they also require significant new investments in people and technology, as well as the creation of a regulatory framework that guarantees fairness and efficiency. In the context of the Green Deal and the new industrial strategy, EU policy focuses on cross-border investment in innovation and activities where the market alone would not take the risk and with a clear desire that public recovery funds do not replace but trigger additional private investments. On the other hand, companies operating in the EU's industrial ecosystems value the challenges and opportunities offered by the green and digital transition as a factor in building a competitive advantage. Businesses are willing to 
invest, but want predictability, a stable regulatory framework, access to capacity and infrastructure, financing innovation, introducing new raw materials and decarbonised energy, supporting demand for climate-neutral products and industries.

The concept of the circular economy, the efforts to create a sustainable product design, increase the collection and recycling of raw materials, as well as the creation of an efficient functioning market for secondary raw materials remain key to the development of companies, but all these actions need advice and financial support [2]. Support may be linked to the development of joint projects between EU countries, increased investment under the Mechanism for Recovery and Sustainability, pooling of private and public funding for innovation in low-carbon technologies and processes, horizontal and vertical agreements between companies for research and development for sustainability and exchange of information, creation of industrial unions, in which the inclusion of start-ups and SMEs occupies a special place and attention. Investing in people, skills, knowledge and learning is an important component of green and digital transformation and a factor in mobilizing the private sector and other stakeholders to improve the skills and retraining of the workforce in Europe.

From this point of view, the aim of the study is:

1) Analysis of the problems related to the need to accelerate the green and digital transformation in the construction market,

2) Development of models that support and ensure the double transformation in the construction market.

\section{PROBLEMS RELATED TO THE NEED TO ACCELERATE THE GREEN AND DIGITAL TRANSFORMATION OF THE CONSTRUCTION MARKET}

The green transformation of the construction market can be the result of creating a construction product that meets the principles of sustainable construction. Sustainable construction aims to restore and maintain harmony between the natural and the built environment, to create settlements that promote human dignity and economic justice [3]. For this purpose, the activity of the construction company must be based on the following several principles: reduction of used resources, reuse of resources, use of recycled materials, reduction of environmental pollution, exclusion of the use of toxic materials, low maintenance costs of construction sites and an emphasis on quality. These principles apply to all stages of the life cycle of a constuction object (design, construction, maintenance, operation, reconstruction, removal/demolition) and are applicable to both the resources needed for construction (land, materials, water, energy and ecosystem) and to the management of construction processes, which are based on total quality management.

The implementation of this task requires a high degree of knowledge, competencies and interaction between all participants in the construction process. In practice, significant changes are required in the organization of construction activities - a comprehensive approach and integration of a wide range of practices for design, construction, operation and maintenance.

The complex connections and relations between the companies-participants in the vertical chain of value creation in construction, objectively impose the need for their improvement and more effective management. A partnership is needed, which means a joint approach of customers, contractors and subcontractors in order to optimize costs, create higher added value at each stage of the chain, by deepening the specialization and differentiation of each intermediate product, improving the quality of the final product, 
which can ensure economic, social and environmental efficiency of construction. Therefore, one of the main obstacles that needs to be overcome is the break with the traditional approach of relationships in the vertical chain of connections and relationships. Green transformation requires the implementation of a policy of creating and managing an integrated vertical chain of relations based on competition, which covers the entire construction process (from production and supply of materials, production of intermediate product, to the creation of the final product, its sale to the end user, use, destruction, recycling, reuse). Efficiency is achieved through cooperation and long-term contracts, longterm relationships, teamwork, information exchange and trust.The realization of the green transformation of the construction market starts from the earliest stages of the project and requires the responsible involvement of all participants in the process: investors and clients, architects, designers, designers, construction companies and contractors, suppliers of raw materials, administrative authorities, researchers, which in practice means significant changes in the organization, coordination and management of the construction company at all levels.

One of the main levers through which the application of the principles of the circular economy, sustainable construction, reduction of carbon emissions should be ensured is the digitalization of the construction market. This is an important factor in achieving the objectives of the "European Green Deal", related to increasing energy efficiency, the introduction of electronic passports for construction sites, balancing the energy system through the use of renewable energy sources and smart grids to manage energy consumption in buildings and facilities.

The digital transformation in construction is among the most current topics at the moment, because it means faster pace and higher quality of construction design and execution, reduced energy consumption, more protected environment and higher quality of life. The process should cover the entire life cycle of the construction product - creation of 3D models of construction products, digital databases for the characteristics of the used construction materials, electronic passports of the buildings and facilities and the respective databases for them, management of the construction and installation works during the execution, management of the operating costs of sites, their repairs, renovations and demolition.

Digitalisation in construction also necessitates the active exchange of information between construction companies, suppliers and investors, management of shared databases, construction of infrastructure in accordance with the requirements introduced on the European market, as well as amendments to legislation and developing a guide for collecting, managing and sharing information, security and control of access to information based on ISO and CEN standards. Central to the digital transition of the construction market is the introduction of a mandatory requirement for the use of Building Information Modeling (BIM) in the development and implementation of all projects/sites.

Based on information and knowledge, the system of information modeling of buildings presents in digital form the physical and functional characteristics of the respective construction object, which is a reliable basis for making effective decisions throughout the life cycle - from idea, concept, project, operation to destruction. The aim is to create a virtual information model of the whole team (architects, landscape architects, surveyors, constructors, civil engineers, etc.), which is offered for analysis and evaluation of the investor, suppliers, contractor and subcontractors, and finally the owner/building manager. This is an effective way for the construction team to integrate and work together to reduce errors and unnecessary changes, transaction costs in the transmission of information within the vertical supply chain. 
The implementation of the double transition - green and digital transformation of the construction market requires the introduction of new models to improve the level of communication and partnership between all participants in the construction process, both formally through agreements and informal relationships.

\section{MODELS THAT SUPPORT AND ENSURE THE DOUBLE TRANSFORMATION IN THE CONSTRUCTION MARKET}

\subsection{Sustainable Supply Chain Management (SSCM)}

Sustainable supply chain management (SSCM) is defined as the management of material, information and capital flows, and cooperation between companies in the supply chain, which allows the realization of economic, environmental and social goals (the three dimensions of sustainable development), a function of customer and stakeholder requirements [4].

Green and digital transformation creates new opportunities and sources for corporate development. They are related to the growing importance of intangible assets - information, knowledge, technological know-how, innovation, and their integration and transfer in the supply chain. A particularly valuable source of knowledge today are the partners involved in the supply chain, who share their understandings of sustainable development, application of the principles of the circular economy, opportunities to create new capabilities, competencies, which is a factor in building collective competitive advantages (not just company advantages). The combination of the company's internal training mechanism and access to external sources of knowledge is a factor in realizing the goals. The knowledge shared by the partners in the supply chain allows to timely identify new opportunities or threats in the market, to take appropriate action and is an effective way to share, create, allocate new valuable resources.

The transfer of knowledge in the supply chain includes economics, environmental (reduction of environmental pollution through the development and implementation of new technologies, use of recycled materials, etc.) and social aspects, which by definition are long-term and different from the immediate ones, short-term financial benefits.

Trust between supply chain partners is the most specific asset that allows the development of effective knowledge sharing programs and a mechanism for sustainable supply chain management. The implementation of this process depends on the organization and the participating companies. If there are strong, dominant companies in the chain, the process is realized through clearly developed rules of compliance, standards, product requirements at each stage of the chain and the created final product and control over performance against certain criteria.

The transfer of knowledge into a supply chain in which equal companies participate is realized through direct connections and interactions between the partners in order to collectively develop new processes, products and solutions to complex sustainable problems [5]. This type of knowledge transfer covers a wide range of activities - formal intercompany communications (joint planning, periodic team meetings, employee training programs) and informal - daily exchange of information, problem sharing, experience between individual companies and individual employees, managers working in them. The problems can be both internal and external, usually coming from direct or indirect stakeholders who have the potential to create opportunities and risks for transformation. 
The communication between the companies involved in the supply chain gives them the necessary information in this direction and suggests the necessary actions.

\subsection{Creating a strategic industrial alliance - a factor for the development of SMEs}

The updated EU Industrial Strategy for 2020 focuses on the necessary incentives for the successful development of SMEs through the creation of industrial unions. A common feature of the construction market is the large number of operating small and medium-sized companies, with limited internal, own resources and potential for the realization of the double transition. For these reasons, it is believed that small and medium-sized companies have a significant opportunity for development by merging with other companies and/or creating strategic (industrial) alliances. They are defined as voluntary associations between companies on the basis of contractual relations that allow development and change, through cooperation of production and development of the created final product, through the transfer of technology, knowledge and services [6].

The main goal of creating a strategic alliance is the development of innovative activities related to product development, entering new markets [7]. Unification between companies can ensure more efficient allocation and use of scarce resources and the realization of a synergistic effect in one or most companies, as well as successful adaptation to external changes, integration of external resources through know-how, exchange of knowledge, information, technology and products, which increases overall productivity. These processes allow managers to use more effectively the existing physical, human (experience, knowledge) and organizational (managerial knowledge, vertical connections, etc.) resources, which are the basis for creating higher added value and developing new strategic changes. Building specific, unique relationships between companies participating in such associations, allows the development of their own resources, access to various markets, including territorial, creating new business management models, which is a factor of competitive advantage, higher reputation and stabilization and/or expansion of market positions.

The development and implementation of a common strategy for solving various problems in the strategic union creates significant opportunities for the development of small participating companies. The main factor for the success of the strategic alliance is the clear definition of the external (market, technological, etc.) conditions in which it will develop and on this basis the determination of the tasks and competencies of each participant. This means building an effective internal structure and system of transfer of knowledge, information and successful business behavior from one company to another, which develops the adaptive capacity of each individual company and the union as a whole. The proper integration of external and internal resources ensures the development of effective collective strategies in the conditions of competition between the participating companies and flexible reconfiguration of resources in response to the dynamics of the external environment, which provides the desired end result.

The main factor for success within the established strategic alliance is the presence of internal, distinctive competencies, provided with the necessary physical assets. The company leader, a key player determines the standards, requirements for the product created at each stage of the overall production. Under these conditions, the small company must develop its competencies and capabilities in the direction of increasing productivity and efficiency within the limits and rules thus defined. Deepening specialization is a key component of its strategic behavior. The basis for this are the opportunities to acquire additional assets through the exchange of technology, information, knowledge and other 
specific resources in the union and rapid, aggressive adaptation to the requirements of the key player (fig.1).

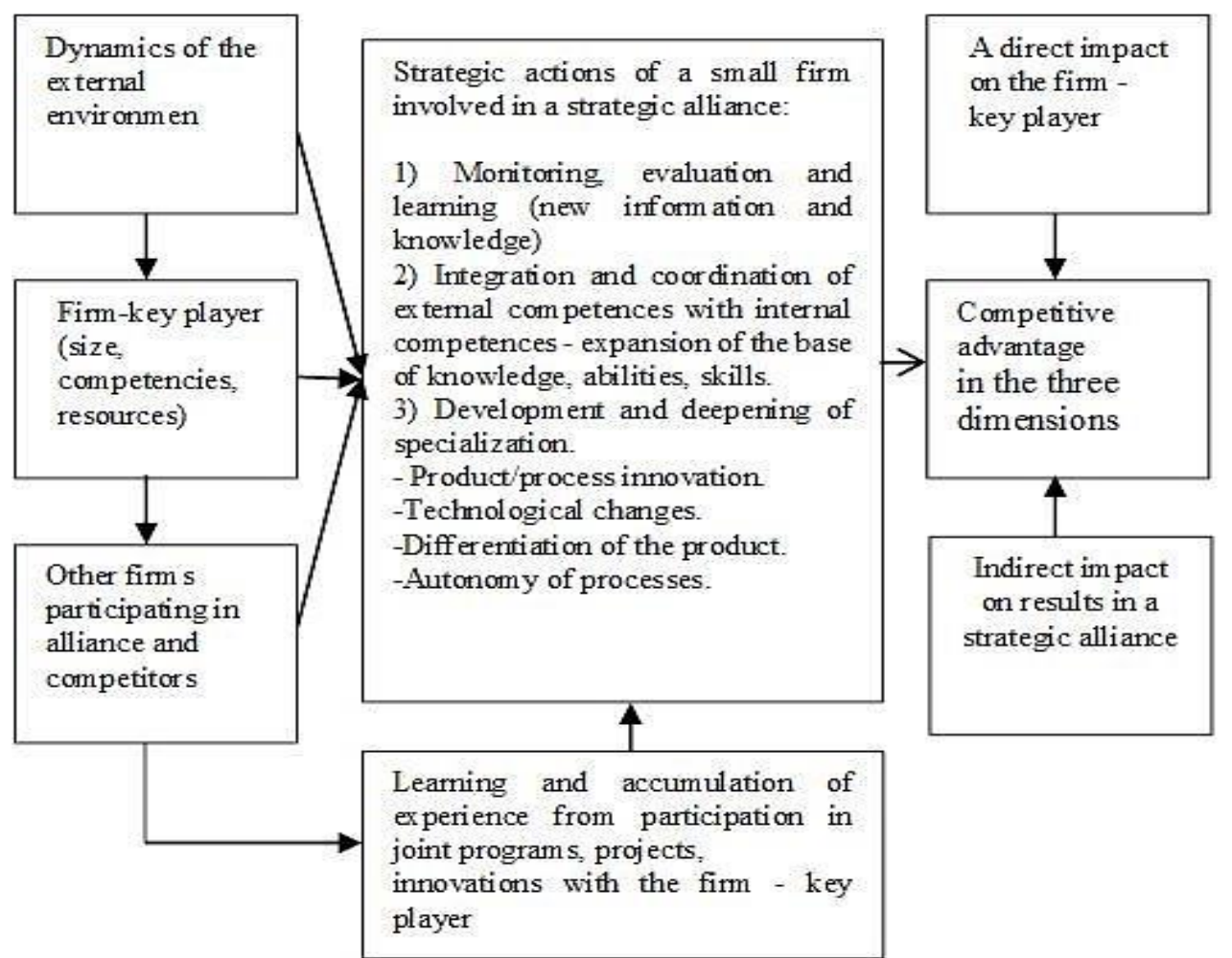

Fig. 1. Model for creating a strategic alliance and managerial actions of the small firm that allow building competitive advantages (in three dimensions) and performance

\subsection{Development of an innovative start-up company}

The new challenges facing construction companies related to the double transition require special attention and the provision of the necessary assistance and support for a new start-up company to successfully adapt to the dynamics of the external environment in order to survive and/or realize growth, taking advantage of its innovations.

The most important characteristic of the new start-up company is the limited capacity and the lack of history, experience, knowledge, routine. Nevertheless, the aim is to integrate external skills and knowledge with internal resources. In a changing external environment, manager in the new company cannot do all this at once, but face the challenge of constantly changing their internal resources, to seek ways for new configuration and reconfiguration of resources. At the heart of this complex process are the entrepreneurial skills and activities of managers, which focus on [8]:

1) Ability to analyze changes in the environment, discover possible alternatives and solve the problem (adaptive ability).

2) Ability to evaluate external information, knowledge, assimilation, dissemination and application (absorptive capacity).

3) Ability to change the way the problem is solved (innovative ability). 
The development of any innovation is the result of the adaptive and absorbing company ability to discover, evaluate external, new knowledge and information, to assimilate and integrate them with its internal knowledge, thus in practice it creates new knowledge (fig.2).

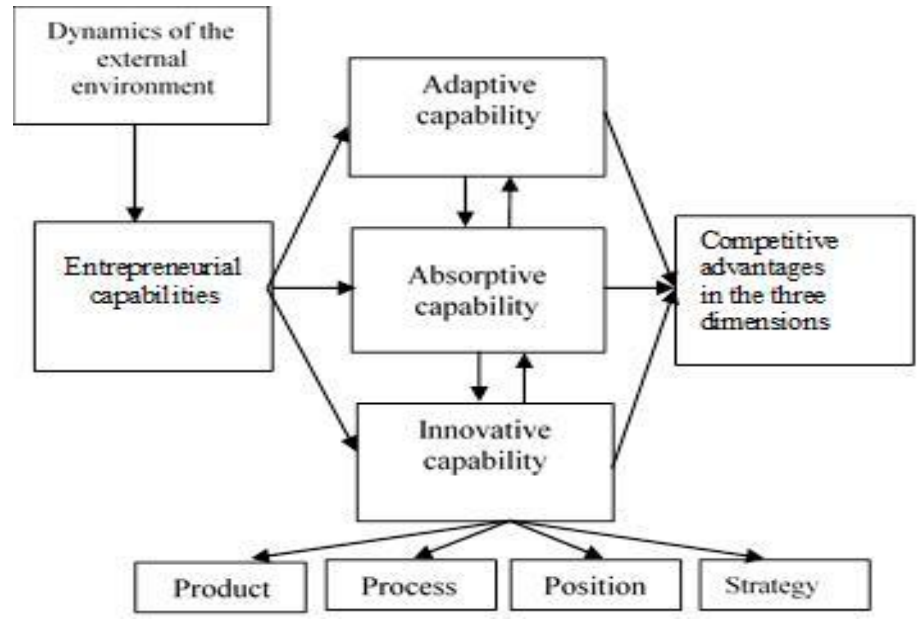

Fig.2. Model of organization and guidelines for development of an innovative start-up company

Absorbent capacity is extremely important for the development of the new company [9]. Firstly, it allows the creation of a long-term vision for development and secondly, the application of new technologies, the creation of a unique product, effective vertical connections and multidisciplinary teams (rather than functional ones). Such a knowledgebased organization is a collection of everything that the company and its employees know or understand, and its operational competencies are what the company and its employees can specifically do. Entrepreneurial capabilities and the development of innovative competencies of the company allows stabilization and strengthening of relationships with customers, suppliers, which stimulates the desired company growth, and over time provides expansion of relationships and development of new technologies with partners, entering new markets. The internal processes in the company related to its organization, culture, selection of employees, encourages staff and their motivation to develop and implement new innovations. The involvement of potential customers in the development of the new product, the cooperation with established organizations, allow easier and faster adaptation to changes in the external environment and in internal resources.

The success of start-ups also depends to a large extent on each country's policy aimed at creating a stable regulatory framework, access to capacity and infrastructure, supporting venture capital in small innovative companies, funding for innovation to create a sustainable construction product, agreements between companies for sustainability and exchange of information on research and development.

\subsection{Construction cluster}

Another model that facilitates the process of green and digital transformation of the construction market and its sustainable development is the construction of a cluster. 
The cluster is a geographically concentrated voluntary association that includes interconnected companies, specialized suppliers of components, equipment and services, as well as specialized infrastructure, intermediaries, government and other institutions (universities, think tanks, agencies, trade associations), which provide specialized training, education, information, research, technical support and whose activity is based on competition and cooperation [10]. The geographical scope of the cluster varies from one region, country, or even one city, and may cover neighboring cities, regions, countries, which is an incentive for cross-border investment.

The main factor ensuring the effective functioning of the cluster is the presence of a core, leading company (often called an anchor), well-developed infrastructure, access to markets, raw materials, social services and financial resources.

The construction cluster as a factor for sustainable construction must include interconnected companies and entities involved in the vertical value chain - construction company with strong positions - leader, investors, end users, architectural and design offices, contractors and subcontractors (with access to the experience of the large, leading company, to "good practices"), manufacturers and suppliers of equipment and raw materials, waste management, recycling companies and creating a market for recycled materials, government and local public institutions, universities, research units, construction organizations, each with well-defined rights and obligations (fig. 3).

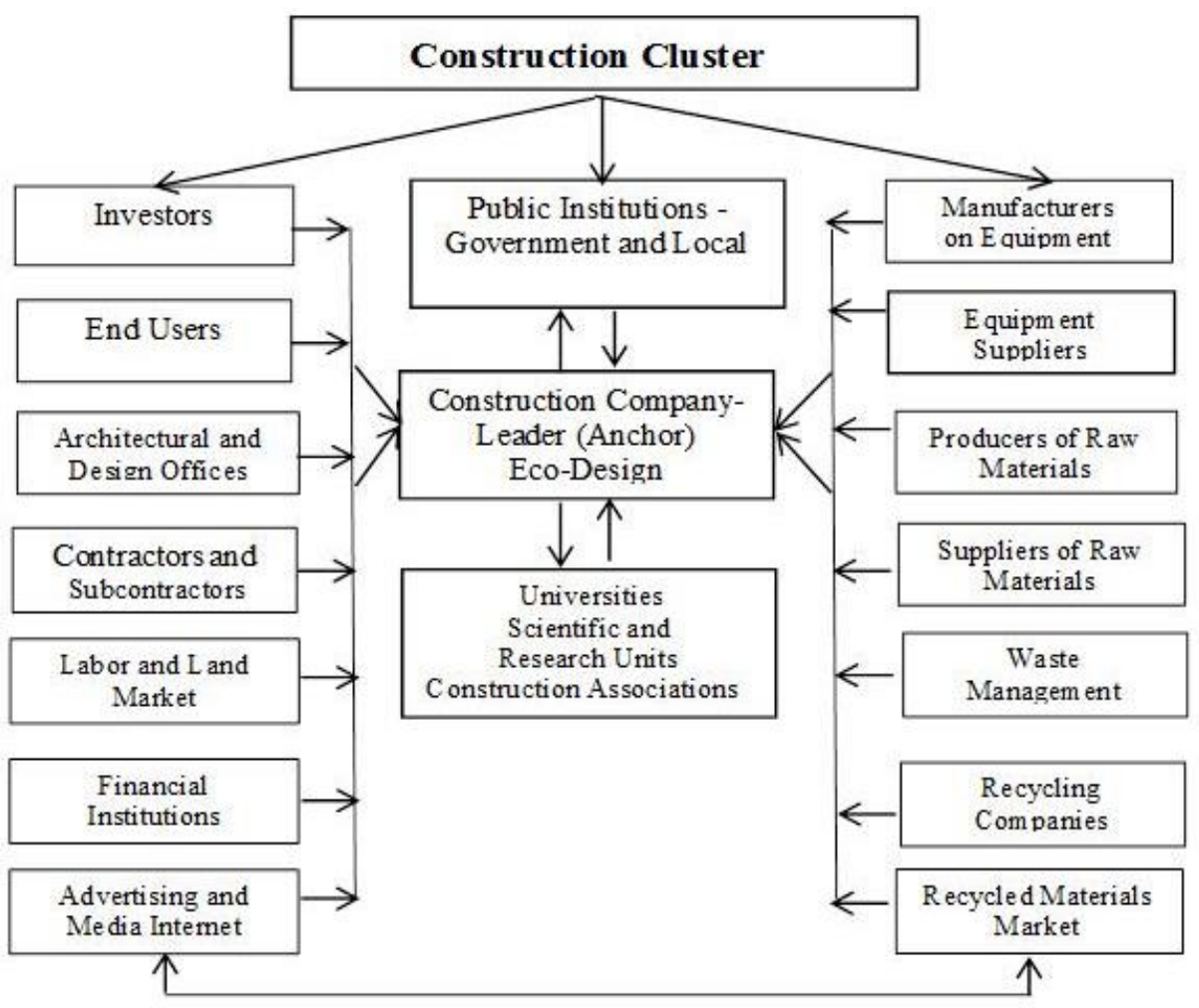

Fig. 3. Structure and organization of the construction cluster - a factor for sustainable development (green and digital transformation) of the construction market and company 
An important starting point in the activity of the cluster is the eco-design of production processes and products so that they can be used longer, repaired, modernized, recycled, instead of being discarded. In this way, the desired circular process can be carried out, which includes all stages of the product life cycle: raw materials, resources $\rightarrow$ product design $\rightarrow$ production $\rightarrow$ consumption $\rightarrow$ reuse $\rightarrow$ waste management $\rightarrow$ recycling $\rightarrow$ creation of new raw materials and resources for others production.

The creation of the construction cluster enables entrepreneurs to take advantage of potentially new product and territorial markets, to provide the necessary skills base on the labor market, and consumers to make rational choices through better information on the environmentally friendly characteristics of different products. In the conditions of a dynamic external environment in the cluster conditions are created for building new connections between interconnected companies and markets, multidisciplinary teams, improving the level of communication between the participating companies, developing partnerships, whether formally through agreements or informal relations. In practice, this means creating sustainable integrated vertical management chain, which covers the whole circular process and all involved build connections - up and down. The cluster facilitates the process of integration and cooperation between all actors in the vertical chain (customers, companies, suppliers, etc.) and the creation of "open innovations".

The cluster brings together the efforts, potential, resources of the private and public sectors to work together. Public institutions play the role of a mediator between the participating private companies, an initiator of programs and specific implementation plans, a listener of the problems that need to be quickly mastered and resolved. Particularly important for the success of the cluster is the availability of a highly skilled workforce, proximity to research, universities, entrepreneurial spirit and culture that values education and knowledge. These services must be provided by public institutions in close cooperation with all direct and indirect stakeholders.

\section{CONCLUSION}

In the context of the Green Deal and the new EU industrial strategy, companies are facing serious challenges related to the need to accelerate green and digital transformation, which are key to increasing competitiveness and achieving the set goals. The subject of the presented research is the analysis of the double transition on the construction market and the development of models that support and ensure this process.

The author's research shows that the green transformation of the construction market can be the result of creating a construction product that meets the principles of sustainable construction. The implementation of this task requires a high degree of knowledge, competencies and interaction between all participants in the construction process, creating an integrated vertical management chain and applying integrated design principles that bring together key entrepreneurs and professional designers to work together from start to finish.

The digital transformation in construction is among the most current topics at the moment, because it means faster pace and higher quality of design and execution of construction, reduced energy consumption, more protected environment and higher quality of life. Central is the introduction of a mandatory requirement for the use of Building Information Modeling (BIM) in the development and implementation of all project/sites, which provides a comprehensive analysis of the life cycle of the construction product (from idea to demolition, recycling and reuse) and is an effective way to integrate and work with 
the construction team. In this regard, the author develops several models (sustainable supply chain management, creation of strategic, industrial union as a factor for SME development, development and support of an inovative start-up company, creation of a construction cluster), which can facilitate the double transformation in the construction market. What all the proposed models have in common is the exceptional place and role that the exchange, transfer of information, knowledge and continuous learning have as a major factor for the success of the construction company.

\section{REFERENCES}

[1] European Commission. (2021). Updating the 2020 Industrial Strategy: Towards A Stronger Single Market for Europe's Recovery, https://ec.europa.eu/commission/presscorner/detail/en/ip [2] Doneva, D. (2020). New trends in natural resources productivity in Bulgaria. Proceedings of University of Ruse-2020, vol. 59, book 5.1., 156 - 161, http://conf.uniruse.bg/bg/docs/cp20/5.1/5.1-27.pdf

[3] Du Plessis, C. (2002). Agenda for Sustainable Construction in Developing Countries: A discussion document, Report for CIB and UNEP

[4]. Seuring, S. \&. Müller, M. (2008). From a literature review to a conceptual framework for sustainable supply chain management. Journal of Cleaner Production, 16(15): 1699-1710

[5.] Lee, S. \& Klassen, R. (2008). Drivers and enablers that foster environmental management capabilities in small- and medium-sized suppliers in supply chains. Production and Operations Management, 17(6): 573-592

[6]. Gulati, R. (1998). Alliances and networks. Strategic Management Journal, Vol. 19, pp. 293-331

[7]. Eisenhardt, K. \& Martin, J. (2000). Dynamic capabilities: What are they, Strategic Management Journal, 21(10/11), pp. 1105-1121

[8]. Zahra, A., Sapienza, J. \& Davidsson, P. (2006). Entrepreneurship and Dynamic Capabilities: A Review, Model and Research Agenda. Journal of Management Studies, 43(4), pp. 917-955, http://eprints.qut.edu.au

[9]. Wang, C. \& Ahmed, P. (2007). Dynamic capabilities: A review and research agenda. International Journal of Management Reviews, 9(1), pp. 31-51

[10]. Porter, M. (1990). The Competitive Advantage of Nations, New York: The Free Press

\section{Note:}

Aneta Marichova - University of Architecture, Civil Engineering and Geodesy, 1, Hristo Smirnensky Boulevard, 1046-Sofia, Bulgaria (corresponding author to provide e-mail:aneta.marichova@abv.bg. marichova_fte@uacg.bg) 